\title{
Some results of S-transform analysis of the transient planetary-scale wind oscillations in the lower thermosphere
}

\author{
Yu. I. Portnyagin ${ }^{1}$, E. G. Merzlyakov ${ }^{1}$, Ch. Jacobi ${ }^{2}$, N. J. Mitchell ${ }^{3}$, H. G. Muller ${ }^{4}$, A. H. Manson ${ }^{5}$, \\ W. Singer ${ }^{6}$, P. Hoffmann ${ }^{6}$, and A. N. Fachrutdinova ${ }^{7}$ \\ ${ }^{1}$ Institute for Experimental Meteorology, Obninsk, Russia \\ ${ }^{2}$ Institute for Meteorology, University of Leipzig, Germany \\ ${ }^{3}$ Department of Physics, University of Wales, Aberystwyth, U.K. \\ ${ }^{4}$ Cranfield University, RMCS Shrivenham, Swindon, U.K. \\ ${ }^{5}$ Institute for Space and Atmospheric Studies University of Saskatchewan,, Saskatoon, Canada \\ ${ }^{6}$ Institute of Atmospheric Physics, Kuehlungsborn, Germany \\ ${ }^{7}$ Kazan State University, Kazan, Russia
}

(Received July 28, 1998; Revised February 8, 1999; Accepted April 20, 1999)

\begin{abstract}
Technique appropriate to the analysis of lower thermospheric wind data recorded by global-scale networks of ground-based instruments are discussed. The S-transform technique is shown to be effective in the analysis of the main features of travelling planetary waves and this method is applied to the time series of horizontal-velocity data obtained during the DYANA campaign (January-March, 1990). The analysis reveals strongly transient behavior of the day-to-day lower thermosphere wind variations, as well as their specific longitudinal structure. In particular, it was found that the revealed quasi-15 day and quasi-5 day wind oscillations may be described as transient westwardpropagating waves with zonal wavenumber $s=1$, while an oscillation with the a period near 7 days is tentatively identified as having a wavenumber $s=0$.
\end{abstract}

\section{Introduction}

Wind oscillations with periods in the range of 2 days to a few weeks are frequently observed in the lower thermosphere $(80-110 \mathrm{~km})$. There is evidence that at least some of these oscillations are global in nature and related to planetary waves, observed in the troposphere and stratosphere, e.g. Vincent (1990). Following the initial work by Glass et al. (1975), several attempts have been made to determine the global scale structure of day-to-day lower thermosphere wind oscillations: Muller and Nelson (1978), Craig et al. (1983), Clark et al. (1994), Singer et al. (1994), Forbes et al. (1995), Meek et al. (1996). It has been found that the most frequently observed wind oscillations with periods near 2,5 , 10 and 16 days all correspond to predicted resonant frequencies of atmospheric disturbances associated with westwardpropagating Rossby normal modes.

To determine the amplitudes, phases and periods of such waves from ground-based observations, the usual analysis technique consists of applying standard spectral and harmonic methods, such as a Fourier or Lomb-Scargle periodogram analysis, to the recorded time series of wind data. From the calculated phase differences between a number of observing stations the zonal wave-number can be determined. Usually it is precluded that during the period to be analyzed the oscillation is stationary. However it is now well known

Copy right $($ C The Society of Geomagnetism and Earth, Planetary and Space Sciences (SGEPSS); The Seismological Society of Japan; The Volcanological Society of Japan; The Geodetic Society of Japan; The Japanese Society for Planetary Sciences. that many members of the planetary-wave field in the lower thermosphere exhibit significant variability on time scales ranging from a few days to seasonal. In other words, the wave activity displays nonstationary characteristics, i.e. its spectral composition may change with time, and particular wave modes can often be thought of as occurring in so-called $\langle\langle$ bursts $\rangle$ or $\langle\langle$ events $\rangle$ of limited duration. Consequently, a more sophisticated method of analysis is necessary to investigate on a global scale the occurrence, persistence, and temporal variability of wind fluctuations with periods of a few days to around 3 weeks. One such method of analysis of non-stationary wind fluctuations is the short-term Fourier transform, discussed by Kamalabadi et al. (1997). In the present work we demonstrate the application to the global-scale analysis of lower-thermospheric wind data of an alternative method, the S-transform, previously described by Stockwell et al. (1996) and Fritts et al. (1998). In the demonstration we use data from global-scale measurements made in January-March 1990 as part of the DYANA (Dynamics Adapted Network) campaign. This type of data is particularly timely in view of the global-scale observations expected to be made as part of the PSMOS (Planetary-Scale Mesopause Observing System) project.

\section{Data Analysis}

To demonstrate the proposed S-transform approach to the of analysis of global scale winds we examined data obtained during the DYANA campaign of January-March, 1990. From this period we considered data in the form of hourly-mean 
winds, simultaneously measured by meteor-radar, MF-radar and LF techniques in a rather narrow latitudinal belt at heights between about $90-100 \mathrm{~km}$. The locations and types of instruments used to record the data are given in Table 1. As it is well known, each of these instruments have some limitations in determination of the wind magnitudes, and this would give a certain problem in determining the absolute amplitudes but not the phases and periods. As to the amplitudes, our analysis is mainly confined the temporal variations of the relative amplitudes.

The data have been analyzed to reveal the planetary scale features in the day-to-day variations of the different wind parameters. Two complementary methods of analysis were used: firstly, the well-known periodogram and FFT spectral analysis technique and, secondly, the S-transform technique. The periodogram and spectral analysis were used to reveal the main spectral components of the wind oscillations only. In view of the anticipated transient nature of some of the planetary waves, the S-transform technique offers a powerful insight into the spectral composition of the wind field. The S-transform is closely related to the continuous wavelet transform (CWT), and is in effect a 《 phase correction $\rangle$ of the CWT, but its localizing function (a Gaussian) has nonzero mean (Stockwell et al., 1996, Fritts et al., 1998). The advantages of this method lie in its direct connection to the Fourier-transform, and the better temporal and frequency resolution compared to the short term Fourier transform. Also, the S-transform permits determination of the absolutely referenced phase of a particular oscillation as a generalization in the nonstationary processes (Stockwell et al., 1996).

In the present study, the hourly-mean wind data for each station were first transformed to six hourly-mean wind data, interpolated and filtered using a band-pass filter with the high-frequency cut-off corresponding to a period of 2 days and lower-frequency cut-off corresponding to a period of 50 days. To fill gaps in the time series we used a least-squares fitting of the neighboring values by second degree polynomial with exponentially decreasing weights. The phase of a particular oscillation (calculated from the S-transform) at each of the different instrument locations enables the corresponding longitudinal structure of the oscillation to be deduced.

Table 1. Data base.

\begin{tabular}{lccc}
\hline Station & Latitude & Longitude & Method \\
\hline Sheffield & $53^{\circ} \mathrm{N}$ & $4^{\circ} \mathrm{W}$ & $\mathrm{MR}^{*}$ \\
Kuehlungsborn & $54^{\circ} \mathrm{N}$ & $12^{\circ} \mathrm{E}$ & $\mathrm{MR}^{*}$ \\
Collm & $52^{\circ} \mathrm{N}$ & $15^{\circ} \mathrm{E}$ & $\mathrm{LF}$ \\
Obninsk & $55^{\circ} \mathrm{N}$ & $37^{\circ} \mathrm{E}$ & $\mathrm{MR}^{*}$ \\
Volgograd & $49^{\circ} \mathrm{N}$ & $44^{\circ} \mathrm{E}$ & $\mathrm{MR}^{*}$ \\
Kazan & $56^{\circ} \mathrm{N}$ & $49^{\circ} \mathrm{E}$ & $\mathrm{MR}$ \\
Saskatoon & $52^{\circ} \mathrm{N}$ & $107^{\circ} \mathrm{W}$ & $\mathrm{MF}$ \\
\hline
\end{tabular}

*:-station without height resolution.

\section{Results and Discussion}

The periodograms (not shown) calculated for each of the stations reveal significant peaks which are consistent with those derived elsewhere for the DYANA campaign by Singer et al. (1994). It should be noted that, according to these authors, the day-to-day variability observed in the recorded winds at the stations in Western and Central Europe (Sheffield, Kuehlungsborn, Juliusruh and Collm) was quite similar. The stations in Eastern Europe (Obninsk, Volgograd and Kazan) also revealed a similar wind variability with a generally good correlation between the data for this region, but a rather different pattern to those for the stations in Western and Central Europe, indicating a horizontal scale of about $1000 \mathrm{~km}$ for these variations.

Further evidence of the complex longitudinal structure of the day-to-day variations, which are usually considered as a manifestation of a planetary wave propagation in the lower thermosphere, was obtained using the S-transform analysis described above. Figures 1-4 present spectrograms of amplitude squared as a function of time and frequency derived by this technique for the zonal and meridional winds recorded at Saskatoon and Sheffield (Fig. 1), Kuehlungsborn and Collm (Fig. 2), Obninsk and Kazan (Fig. 3) and Volgograd (Fig. 4). The data set from each station used in the analysis had differing qualities (but the sum of the gaps didn't cover greater then $16 \%$ of a time series). So, to be sure that gaps present in some of the data did not significantly contaminate the Stransform results, the S-transform was applied to the data from Obninsk which had artificial data gaps deliberately inserted. The artificial gaps were placed at the same times as the gaps found in the Kazan data and this resulted in that the contents of gaps has increased from $8 \%$ to $18 \%$ in the Obninsk series. Comparison of the original and modified Obninsk data (Figs. 3a) and 3b); 4c) and 4d)) shows that even with the degraded data, the broad features of the spectrograms are conserved. A comparison with the data from the relatively nearby site at Kazan (Figs. 3c) and 3d)) reveals significant differences in the spectral composition of the motion field between these two sites and suggests that the discrepancies represent genuine geophysical differences.

Inspection of Figs. 1-4 reveals a number of 〈〈wave events $\rangle$ which appear at various time throughout the campaign period. The transient behavior of these oscillations, which have periods typical of planetary waves, is markedly dissimilar even over the comparatively narrow range of latitudes addressed in this study. However, some common features in their temporal variations are apparent. In particular, during the period of stratospheric warming (between about midJanuary and mid-February; day numbers 15-45) the spectra are usually broader and the powers larger. Also, the most significant oscillations are present only in particular episodes or $\langle\langle$ wave events $\rangle$ and for each station there are certain $\langle\langle$ quiet $\rangle\rangle$ periods when no significant oscillations are observed. We shall now consider particular features observed in the data.

A significant oscillation occurring with a period of about 13-15 days is clearly seen in both the zonal and meridional components of the prevailing wind for all of the stations under consideration. The time at which this oscillation attains maximum amplitude appears dependent on the longitude of the observation. The oscillation first appears over the 
a)

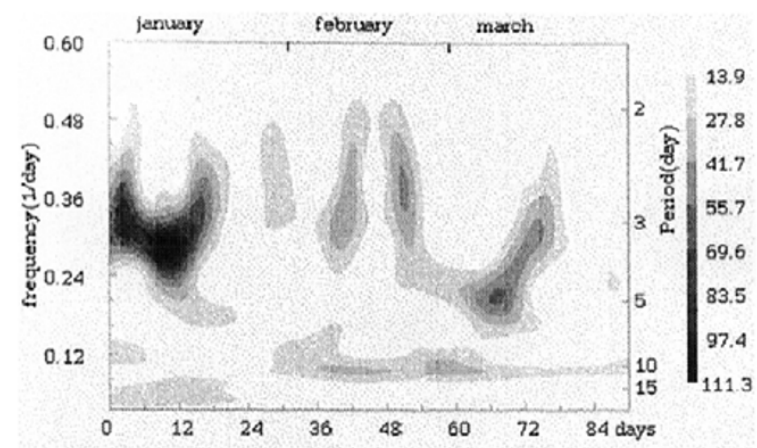

c)

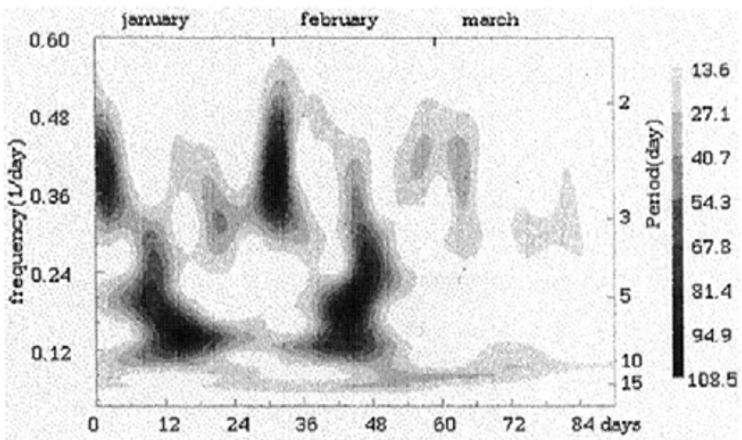

b)

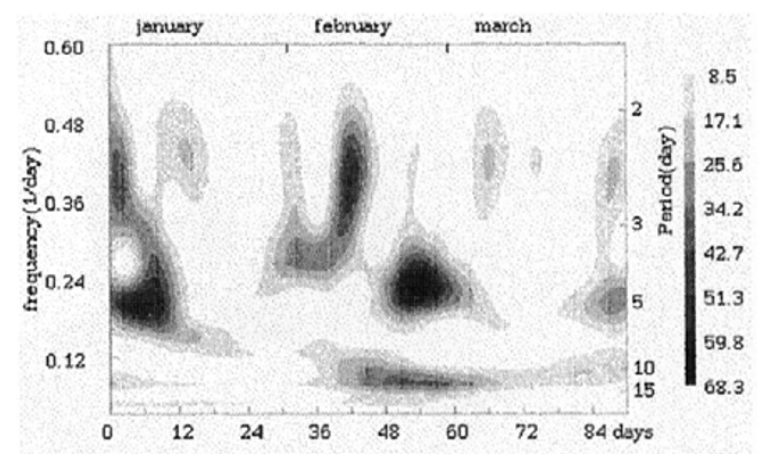

d)

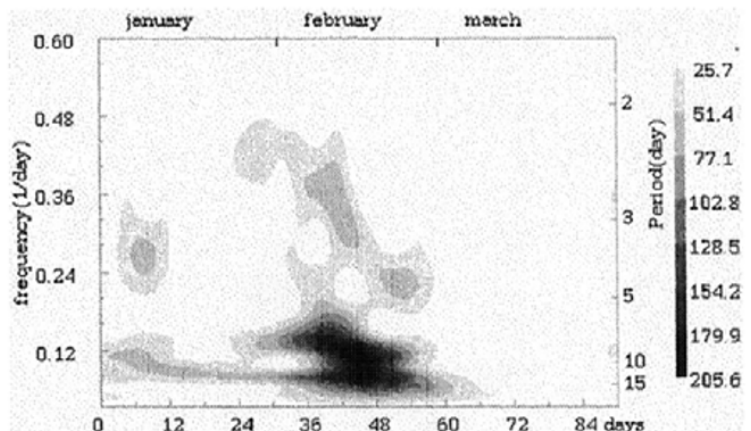

Fig. 1. S-transform results of the measurements from Saskatoon (top) and Sheffield (bottom): a), c) zonal component; b), d) meridional component. The scale is marked in units of amplitude-squared $\left(\mathrm{m}^{2} / \mathrm{s}^{2}\right)$.

a)

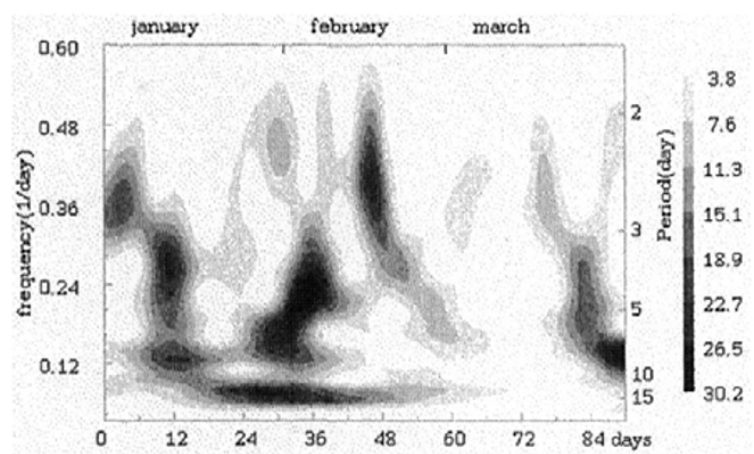

c)

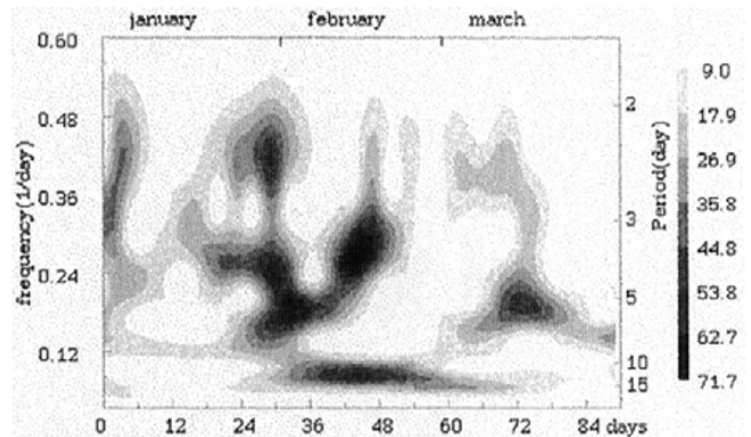

b)

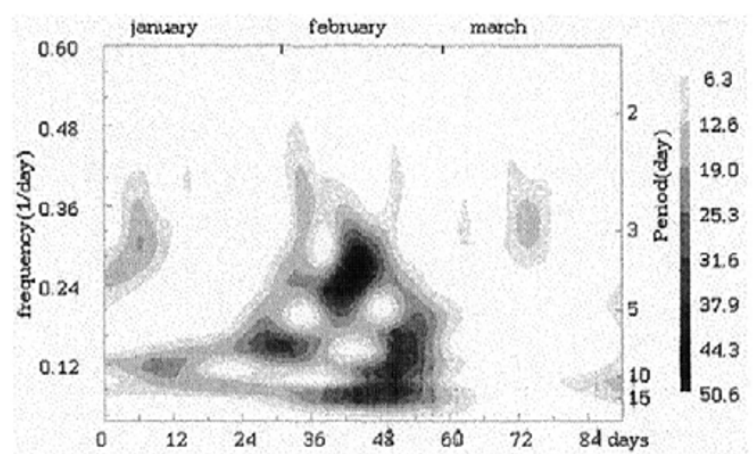

d)

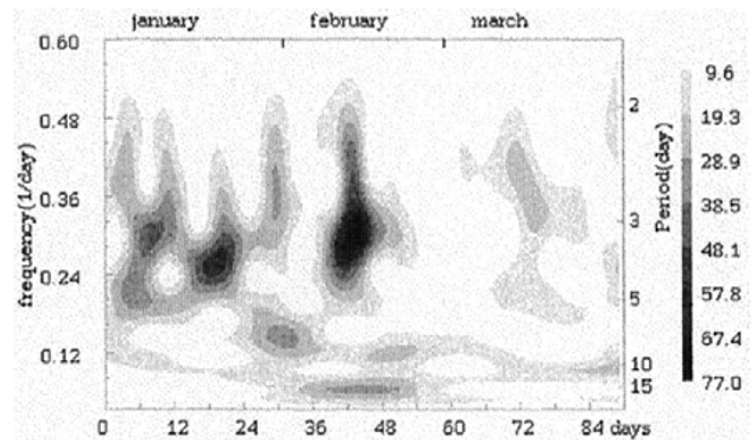

Fig. 2. As for Fig. 1, but with measurements from Kuehlungsborn (top) and Collm (bottom): a), c) zonal component; b), d) meridional component. 
a)

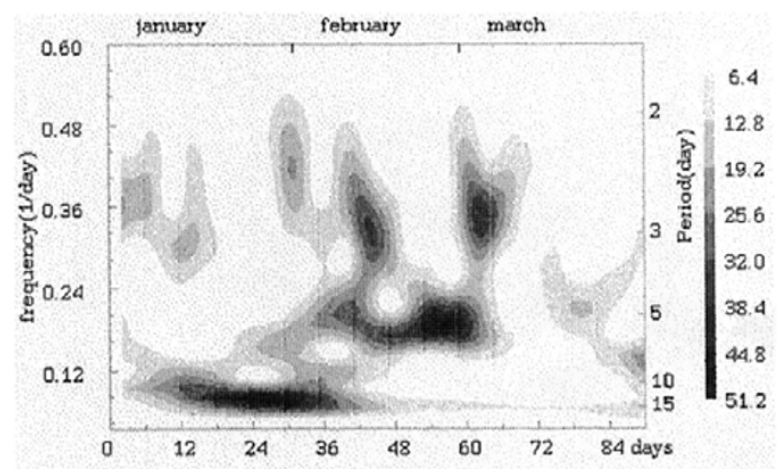

c)

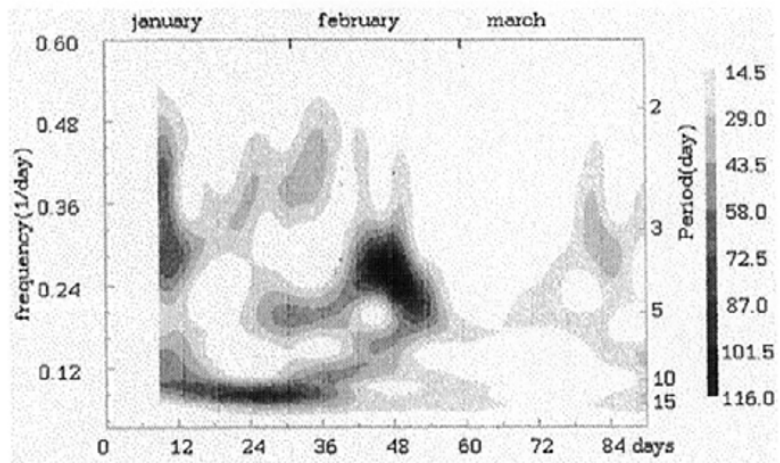

b)

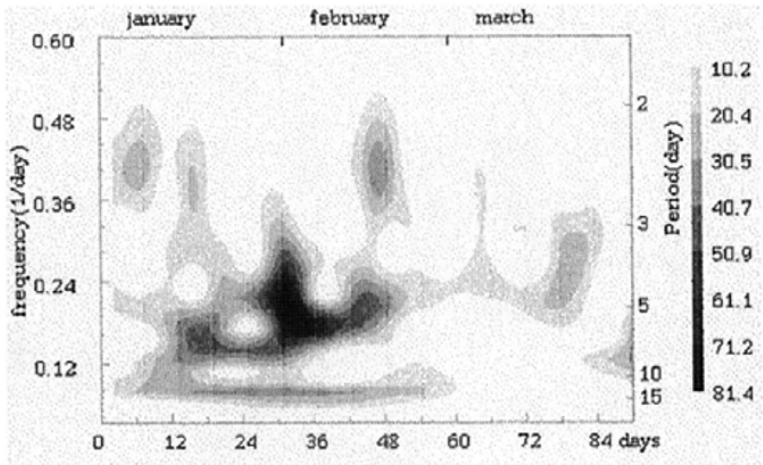

d)

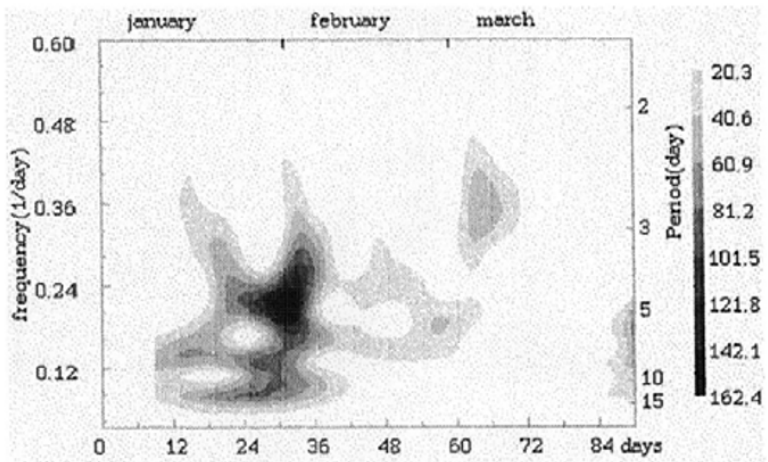

Fig. 3. As for Fig. 1, but with measurements from Obninsk (top) and Kazan (bottom): a), c) zonal component; b), d) meridional component.

a)

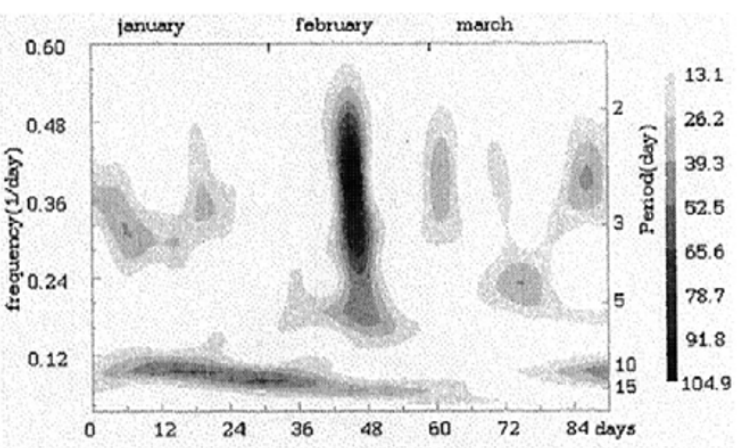

c)

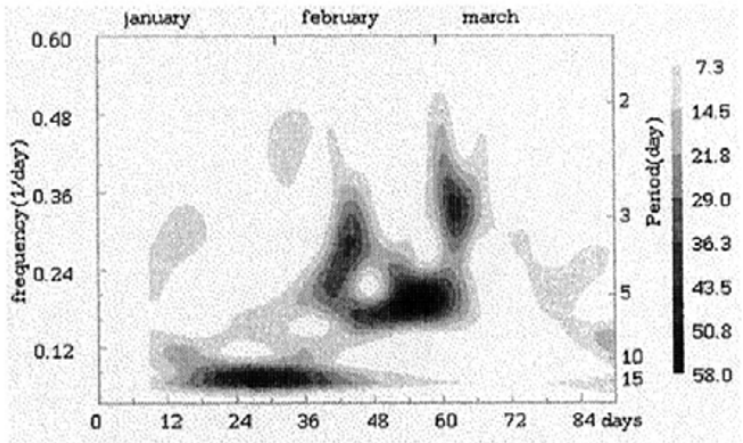

b)

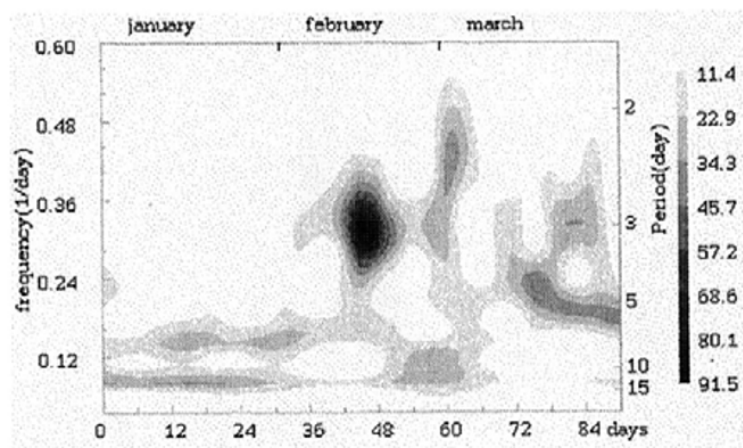

d)

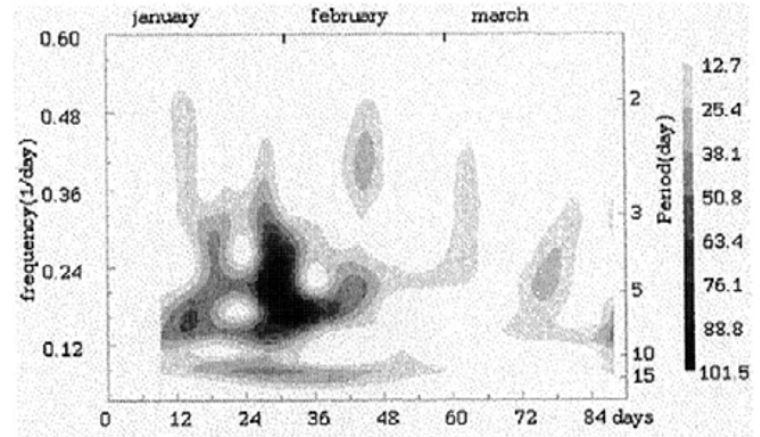

Fig. 4. As for Fig. 1, but with measurements from Volgograd (top) and Obninsk with artificial gaps (bottom): a), c) zonal component; b), d) meridional component. 
Eastern European sites (Obninsk, Volgograd and Kazan) and then over the Western and Central European sites (Sheffield, Kuehlungsborn and Collm). However, the longitudinal dependence of the initial phase of this oscillation, presented in Fig. 5a), shows a rather regular behavior. The slope of the fitted lines (determined by the least-squares method) is equal to $1.05 \pm 0.17$ for the zonal winds and $1.37 \pm 0.2$ for the meridional winds; and these lines are indicated in the figure. Both of these slopes thus strongly indicate a westward-propagating wave with zonal wavenumber $s=1$. This oscillation may be connected with the Doppler-shifted appearance of the well known normal mode 16-day oscillation. Another possible source of this oscillation is a hemispheric $13.8 \mathrm{~d}$ oscillation, propagating from below and apparently controlled by solar activity as shown by Ebel et al. (1978). It is worth noting that oscillations with a similar periods were also detected in temperature variations during the DYANA campaign (Bittner et al., 1994). A comparison between the results of S-transform and sliding least-squares fit for this wave is shown in Table 2 (the least-squares fit errors are shown in brackets). The initial phases presented in this table were calculated at one middle point for all stations. The columns $\langle\langle$ time of max $\rangle$ show the moments (days), at which the wave's amplitude attains its maximum.

A second significant oscillation clearly revealed at the different longitudes is that with a period near 5 days. This oscillation is apparent in both the zonal and meridional wind data of Figs. 1-4, although it is more distinct in the meridional, rather than zonal component. This oscillation shows an even more transient behaviour in comparison to the above discussed 13-15 day oscillation. To investigate these oscillations in more detail we divided the data into groups of similar apparent wave periods and time of appearance. This resulted in consideration of a wave of period about 5.3 day in the data from Obninsk and Kazan, and a wave with a period of about 4.3-4.4 days in the data from Sheffield and Saskatoon. For each pair of sites the observed phases, presented in Fig. 5b), correspond to a zonal wave numbers $s=1$, but for Obninsk and Kazan (slope is equal 1.29) this wave feature occurs before the main warming and for Sheffield and Saskatoon (slope is equal 0.85) it occurs afterwards. The interval between the observation of the wave at the two pairs of stations is equal to about 20 days and during this interval the occurrence of a warming distorts the 5-day wave, namely 3.7-4 days oscillations were observed around 12 February at Collm and Kuehlungsborn. The DYANA campaign study of Bittner et al. (1994) clearly revealed a nearly monochromatic temperature oscillation of about 5 days (4.2-6.5 days) and this wave was observed at practically all stations. The related study of Sheer et al. (1994) further investigated oscillations with periods near to 5 days and concluded that a 5.8-day oscillation, revealed in the $\mathrm{OH}$-rotational temperature measurements at Yakutsk $\left(63^{\circ} \mathrm{N}, 130^{\circ}\right)$, Andoya $\left(69^{\circ} \mathrm{N}, 16^{\circ} \mathrm{E}\right)$ and Biscarrosse $\left(44^{\circ} \mathrm{N}, 1^{\circ} \mathrm{W}\right)$ during the first part of the DYANA campaign, has only two possible interpretations: namely, a zonal wavenumber of either $s=1$ or $s=2$. However, a 4.7day oscillation observed during the second part of the campaign and documented at Yakutsk, Andoya and El Arenosillo $\left(37^{\circ} \mathrm{N}, 6^{\circ} \mathrm{W}\right)$ was found to be compatible with a westward travelling wave of $s=4$. The only alternative, wavenumber
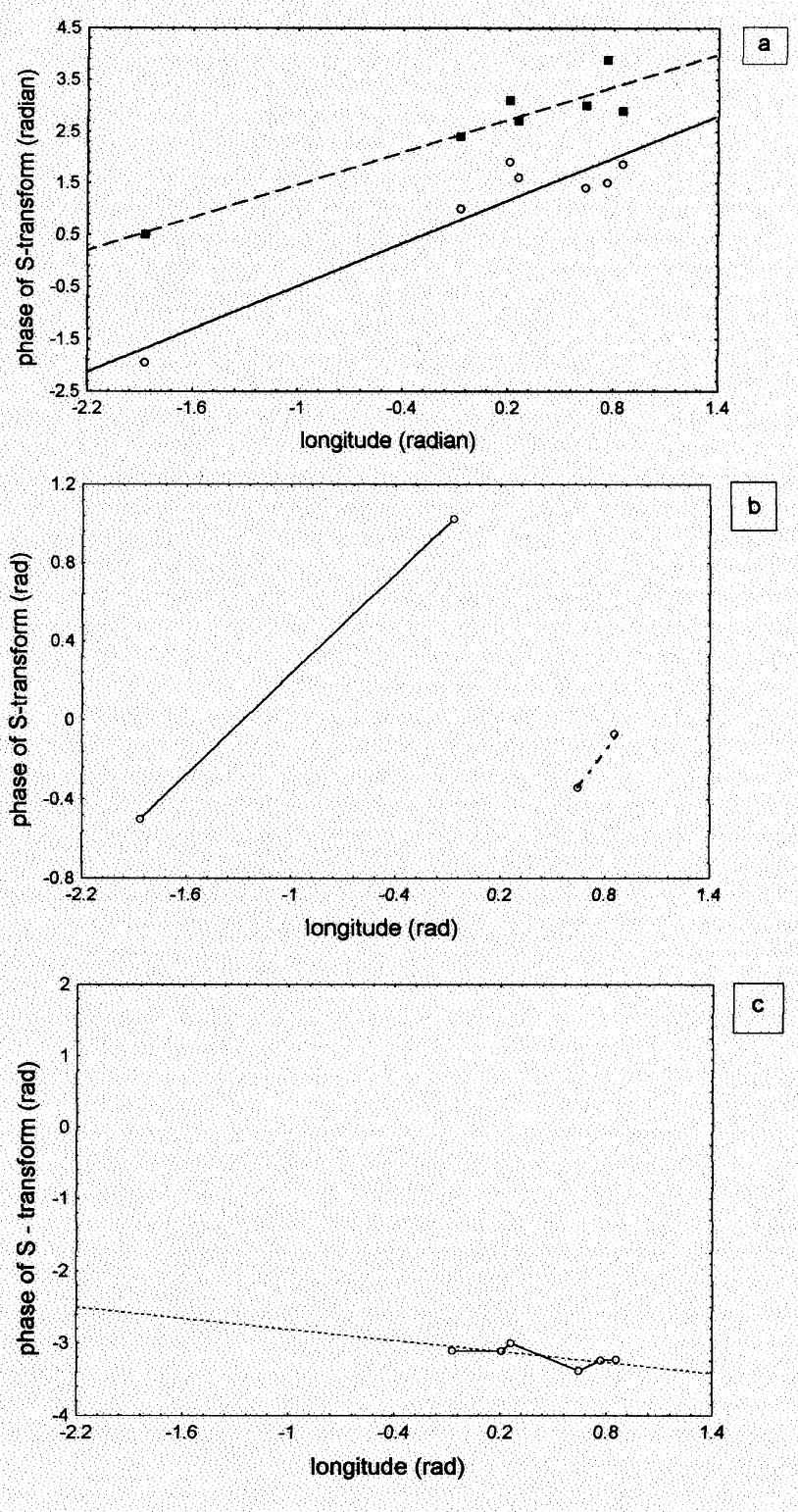

Fig. 5. Phase distribution as a function of longitude for: a) The quasy-13-day wave, solid squares - zonal component, open circles-meridional component; b) The quasy-5- day wave, meridional component only; c) 7-day wave, meridional component only.

1, was not supported by the data at El Arenosillo. However we may note that the latitude of this station is significantly lower than for the other stations considered; and so to form definite conclusions about the zonal wavenumber a more extended data set of winds/temperatures covering a wide range of longitudes and times is needed.

In addition to the traveling planetary-scale oscillations considered above, which are well known from theoretical consideration, an unexpected meridional wind oscillation with apparent zonal wavenumber $s=0$ was revealed. The period of this oscillation is near to 7 days and this disturbance (also rather transient in nature) has significant amplitudes (about $10 \mathrm{~m} / \mathrm{s}$ ) at the all considered measurement sites with the exception of Saskatoon. The halfwidth of a signal, which modulates this wave amplitude is equals to about 11-13 days. The maximum amplitude of the 7-day wave is 


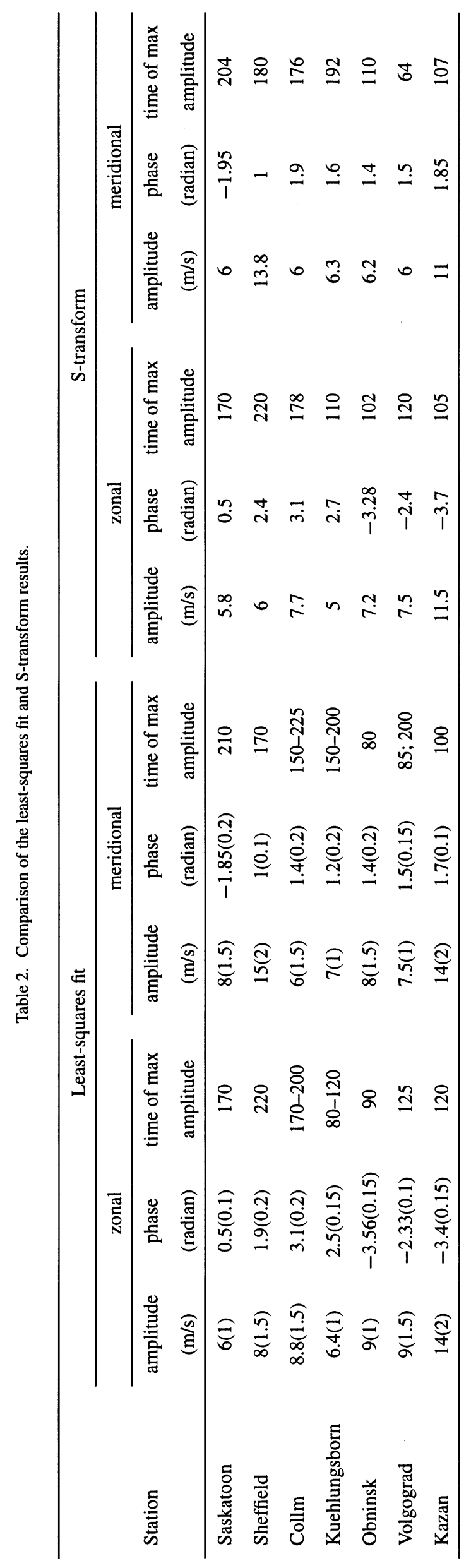


observed in the first week of February, but definitely earlier for the Eastern stations. Figure 5c) represents the phase of this oscillation as a function of longitude. The slope of the fitted line is equal to $-0.2 \pm 0.07$ at a significance level of $95 \%$. This unusual feature appears similar to that reported by Ebel et al. (1978), who observed a global scale wave with the zonal wave number 0 and a period of about 7.5 days in measurements of stratospheric total ozone, detected with the space-born NIMBUS instruments.

The 95\% significance levels of S-transform results were calculated for each oscillation's period separately. The level was constructed with suggestion that a variance of a corresponding data raw is known. The variance was estimated for the data raw without a trend and the tides. It is possible to show that a peak of S-transform amplitude has const $\times \chi^{2}$ distribution if the data raw is a discrete realization of a gaussian noise. Further we use a criteria like the Walker's significance test. A number of independent peaks for a fixed period of wave is estimated as a ratio: the length of the analyzed data raw/two wave's period. The estimated $95 \%$ significance levels which correspond to wave's periods $13-14,6-7$ and 4-5 day, are following: for wind components at Sheffield and Kazan $4 \mathrm{~m} / \mathrm{s}, 8 \mathrm{~m} / \mathrm{s}, 11 \mathrm{~m} / \mathrm{s}$, respectively; at other stations $3 \mathrm{~m} / \mathrm{s}, 6 \mathrm{~m} / \mathrm{s}, 8.5 \mathrm{~m} / \mathrm{s}$. But it is worth to underline that the observed waves have a tendency to gather in the groups of simultaneous appearance. This grouping has very low probability for a random data set.

\section{Conclusions}

The transient nature of planetary-wave oscillations in the lower thermosphere have been revealed using the S-transform technique applied to ground-based radar wind measurements. Data recorded during the DYANA campaign reveals the presence of quasi-15 days and quasi-5 days oscillations which appear to be transient westward-propagating waves with zonal wavenumber $s=1$. Also observed during this campaign was a transient oscillation with a period near to 7 days, tentatively identified as having a zonal wavenumber $s=0$. This study again demonstrates that for the PSMOS campaigns the ground-based wind measurements, well distributed over the globe, are necessary.

Acknowledgments. The impetus for this work was given by Prof. G. Shepherd. The authors are very grateful to him for his constant attention and help in collecting of the data. This work was supported in part by INTAS under grant 96-1669.

\section{References}

Bittner, M., D. Offermann, I. V. Bugaeva, G. A. Kokin, J. P. Koshelkov, A. Krivolutsky, D. A. Tarasenko, M. Gil-Ojeda, A. Hauchecorne, F.-J.
Lübken, B. A. de la Morena, A. Mourier, H. Nakane, K. I. Oyama, F. J. Schmidlin, I. Soule, L. Thomas, and T. Tsuda, Long period/large scale oscillations of temperature during the DYANA campaign, J. Atmos. Terr. Phys., 56, 1675-1700, 1994.

Clark, R. R., A. C. Current, A. H. Manson, C. E. Meek, S. K. Avery, S. E. Palo, and T. Aso, Hemispheric properties of the two-day wave from mesosphere-lower-thermo-sphere radar observations, J. Atmos. Terr. Phys., 56, 1279-1288, 1994.

Craig, R. L., R. A. Vincent, S. P. Kingsley, and H. G. Muller, Simultaneous observations of the quasi 2-d wave in the nothern and southern hemispheres, J. Atmos. Terr. Phys., 45, 539-541, 1983.

Ebel, A., A. Chazi, and W. Batz, Evidence of global scale waves with zonal wave number zero in the stratosphere, Pure Appl. Geophys., 116, 8-31, 1978.

Forbes, J. M., M. E. Hagan, S. Miyahara, F. Vial, A. H. Manson, C. E. Meek, and Yu. I. Portnyagin, Quasi 16-day oscillation in the polar summer mesospheric temperature, J. Geophys. Res., 100, 9149-9163, 1995.

Fritts, D. C., D. M. Riggin, B. B. Balsley, and R. G. Stockwell, Recent results with an MF radar at McMurdo, Antarctica: Characteristics and variability of motions near 12-hour period in the mesosphere, Geophys. Res. Lett., 25, 297-300, 1998.

Glass, M., J. L. Fellous, M. Massebeuf, A. Spizzichino, I. A. Lysenko, and Yu. I. Portnyagin, Comparison and interpretation of the results of simultaneous wind measurements in the lower thermosphere at Garchy (France) and Obninsk (USSR) by meteor radar technique, J. Atmos. Terr. Phys., 37, 1077-1087, 1975.

Kamalabadi, F., J. M. Forbes, N. A. Makarov, and Yu. I. Portnyagin, Evidence for nonlinear coupling of planetary waves and tides in the Antarctic mesopause, J. Geophys. Res., D102, 4437-4446, 1997.

Meek, C. E., A. H. Manson, S. J. Franke, W. Singer, P. Hoffman, R. R. Clark, T. Tsuda, T. Nakamura, M. Tsutsumi, M. Hagan, D. C. Fritts, J. Isler, and Yu. I. Portnyagin, Global study of northern hemisphere quasi-2-day wave events in recent summers near $90 \mathrm{~km}$ altitude, J. Atmos. Terr. Phys., 58, 1401-1411, 1996.

Muller, H. G. and L. Nelson, A traveling quasi 2-day wave in the meteor region, J. Atmos. Terr. Phys., 40, 761-766, 1978.

Scheer, J., E. R. Reisin, J. P. Espy, M. Bittner, H.-H. Graef, D. Offermann, P. P. Ammosov, and V. M. Ignatyev, Large-scale structures in hydroxyl rotational temperatures during DYANA, J. Atmos. Terr. Phys., 56, 17011715,1994

Singer, W., P. Hoffmann, A. H. Manson, C. E. Meek, R. Schminder, D. Kuerschner, G. A. Kokin, A. K. Knyazev, Yu. I. Portnyagin, N. A. Makarov, A. N. Fakhrutdinova, V. V. Sidorov, G. Cevolani, H. G. Muller, E. S. Kazimirovsky, V. A. Gaidukov, R. R. Clark, R. P. Chebotarev, and Y. Karadjaev, The wind regime of the mesosphere and lower thermosphere during the DYANA campaign-I. Prevailing winds, J. Atmos. Terr. Phys., 56, 1717-1729, 1994.

Stockwell, R. G., L. Mansinha, and R. P. Lowe, Localization of the complex spectrum: the S transform, IEEE Trans. Signal Processing, 44, 998-1001, 1996.

Vincent, R. A., Planetary and gravity waves in the mesosphere and lower thermosphere, Adv. Space Res., 10(12), 93-101, 1990.

Yu. I. Portnyagin (e-mail: yportgin@typhoon.obninsk.org), E. G. Merzlyakov, Ch. Jacobi, N. J. Mitchell, H. G. Muller, A. H. Manson, W. Singer, P. Hoffmann, and A. N. Fachrutdinova 